\title{
Technique Development on Baking a Novel Pastry with Nuts Application Xiang DONG ${ }^{1, a}$, Feng TAN $^{1, b}$, Frank Vriesekoop ${ }^{2, c}$, Kexin ZHANG $^{1, d}$, Yang $X U^{1, e, *}$
}

${ }^{1}$ Beijing University of Agriculture, Beijing, China

${ }^{2}$ Harper Adams University, United Kingdom

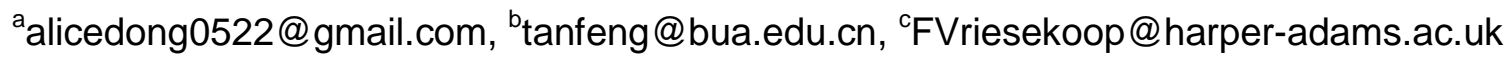

d18500222474@163.com, xuyangswe@126.com, “Corresponding author

Key words: puff pastry, nuts, baking technique

Abstract. Through a series of experiments, it was explored the techniques used in process of puff pastry manufacturing which especially focused on appropriate handlings for introducing nuts into the product. The key sections that influence sensory quality of the product with involvement of nuts were discussed. It was illustrated the key points of recipe in dough mixture, nuts preparation, pasta dough forming, baking and completing in processing of the novel puff pastry.

\section{Introduction}

Puff pastry is a non leavened baking product with unique textural properties of laminated structure with crispy cover and soft inner. It is enjoyable due to sensory experience from not only such texture but also the unique flavour created by combination of dough and fat in baking process. [1] Puff pastry is produced in a wide range such as croissant, sausage rolls, Danish pastry, cream horns and pie tops [2]. Yeast is occasionally added into the dough of Danish and Croissant pastry to enlarge the volume before baking [3]. Puff pastries are popular cross cultures from western to eastern, which distinct for the laminate dough layers of fat by the process of folding and rolling out to make flaky mouth feel and physical properties, and so appealing to customers [4]. Additionally, puff pastry could be produced in wide scales of bakery, such as semi-automated in small to medium scale, or whole automated in large production line [5]. Making puff pastry is complicated by including a wide range of process and practices, while it is also an art of baking production.

Dried fruits can be used as ingredients within or topping of puff pastry [6]. It is rare to see that any nuts to be introduced into pastry product although such ingredients have been widely and successfully used in baking production, which could add value to baked foods by providing nutrition and new flavours. It was reported from clinical trials that appropriate consumption of nuts in weigh-loss could results in a positive role in 2007[4]. Any previous studies introduced the process of puff pastry and outlining affects of nut towards baking food [7]. It was shown that producers had been willing to consider adding various nuts to bread, snack and other baking foods [8]. However, it is challenged that the moisture in dough is hardly to escape due to the barrier of fat layers during baking, and this may encourage water migration into nuts where addressed in puff pastry to lead a negative affect on sensory quality of the product. This research aimed to provide a guideline on the process of making novel puff pastry with injection of nuts and develop techniques on reducing the water migration into nuts. 


\section{Materials and equipments}

The food materials were purchased from a local supermarket including strong flour, weak flour, butter, salt, dark chocolate, milk powder, sugar, egg and nuts. The nuts comprise sesame, cashew, walnut, peanut and almond.

The equipments used in the experiments are: Flour Mixer (B20-G, Shandong Heng Food Machinery Co., Ltd.) and Oven (SK-632TG, Xin Mai Machinery Co., Ltd.).

\section{Process of Making Puff Pastry}

The process of making puff pastry was created in Figure 1.

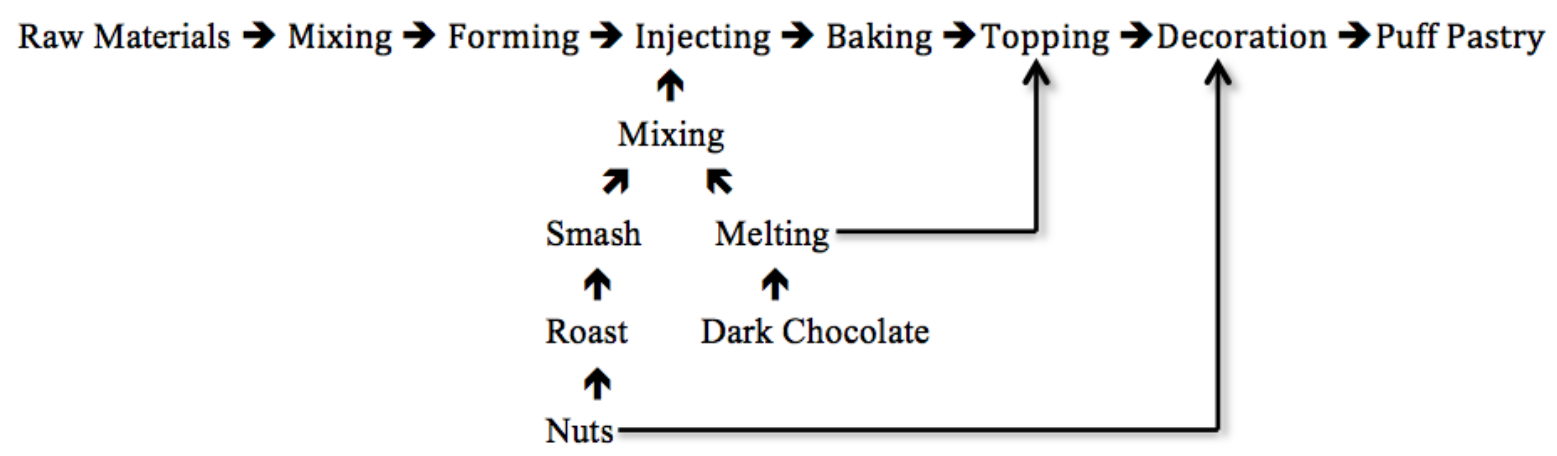

Figure 1. Process of making puff pastry

\section{Technique Points and Discussion}

Recipe and Dough Mixing. The appropriate recipe for the novel puff pastry is displayed in Table1. Flour and other ingredients were initially mixed with water at rotate speed of $113 \mathrm{r} / \mathrm{min}$ for $15 \mathrm{~min}$ to get raw dough, and then incorporated with butter flat to built pasta dough during the next forming section. It was achieved an optimum sensory experience on flavour and texture of the puff pastry, as well as an enjoyable mouth feel of injected nuts.

Table 1 Recipe of dough mixture

\begin{tabular}{llll}
\hline Strong flour & $16 \%$ & Milk powder & $11 \%$ \\
\hline Weak flour & $16 \%$ & Egg & $8 \%$ \\
Butter & $33 \%$ & Sugar & $2 \%$ \\
Water & $13 \%$ & Salt & $1 \%$ \\
\hline
\end{tabular}

The quality of puff pastry could be varying substantially depended on the selection of the raw materials. The weight equivalent in strong and weak flour provided a balance on gluten protein for the dough to achieve an appropriate expanding texture. More weak flour produced the pastry to a low lift, sticky and brittle physical shape due to the lake of tension capability. To the contrary, a higher content of strong flour would easily get the product hardness as the intensive denature of gluten protein [8]. The use of milk powder, egg, sugar and salt not only improved the paste dough in softness, natural colour and lustre but also contributed in flavor of the pastry.

It was observed that the ratio between flour, butter and water had significant impacts on sensory quality of the puff pastry (Table 2). The results indicated that more butter and low water contents could prevent the puff pastry from stickiness and nuts moist. Meanwhile, water is a main factor impacting the hardness of dough. Over watering of dough mixture can get laminated layers too soft 
and adhesion; in contrarily, lack watering may cause cracking from the crispy top of puff pastry [9].

Table 2 Sensory quality impacted by ratio between flour, butter and water

\begin{tabular}{cl}
\hline Flour/Butter/Water & \multicolumn{1}{c}{ Sensory display from the puff pastry } \\
\hline $1.0 / 0.8 / 0.5$ & $\begin{array}{l}\text { A worse sensory experience on the pastry with too sticky, tasteless and } \\
\text { pale; and nuts with soft and wet. } \\
1.0 / 0.8 / 0.4\end{array}$ \\
& $\begin{array}{l}\text { Well physical shape, texture and lustre with the pastry, but still soft, wet } \\
\text { and tasteless with nuts. }\end{array}$ \\
\hline $1.0 / 1.0 / 0.4$ & $\begin{array}{l}\text { Better colour, taste, porosity structure and crispness cover with the } \\
\text { pastry, as well as more crispy nuts fragment with strong roasted flavour. }\end{array}$
\end{tabular}

Preparation of Nuts Fragment. The nuts of sesame, cashew, walnut, peanut and almond were weighted equally after roasting and crashing respectively. The mixture of nuts' fragment then combined into the melt of dark chocolate for the further injection into pasta dough.

Roast was necessary for the nuts losing moisture to decrease the potential of its water absorption from the pasta dough in baking process and enhancing aroma out of the nuts. It was required for different kinds of nut to be roasted under different temperatures and time (Table 3). Additionally, crashing nuts into small piece of flakes was helpful to avoid flattening the laminated structure of the puff pastry.

Table 3 Roast temperature and time to different kinds of nuts

\begin{tabular}{lccccc}
\hline & Sesame & Cashew & Walnut & Peanut & Almond \\
\hline Temperature $\left({ }^{\circ} \mathrm{C}\right)$ & 150 & 200 & 180 & 180 & 180 \\
Time $(\min )$ & 15 & 18 & 18 & 18 & 18 \\
\hline
\end{tabular}

Forming and Nuts Injection. Kneaded the raw dough for 5 minutes to shape into a ball and refrigerated at $4{ }^{\circ} \mathrm{C}$ for 1 hour. Then the dough was rolled out into a $4 \mathrm{~mm}$ thickness slice. Meanwhile, a piece of butter was rolled into a slice at the same thickness, and then it was wrapped by the dough slice. The laminated slices of dough and butter were immediately rolled out into a square sheet of $100 \mathrm{~mm} * 200 \mathrm{~mm} * 6 \mathrm{~mm}$ and folded into pasta dough to be refrigerated at $4{ }^{\circ} \mathrm{C}$ for 20 minutes. Such process from rolling to cooling pasta dough was carried three times in forming section. The final pasta dough was cut into sheets of $60 \mathrm{~mm} * 80 \mathrm{~mm}$ after the rolling out, and injected with the prepared mixture of nuts fragment and chocolate melt from the vertical surfaces to create a core inside.

The folding process of the pasta dough is shown on Figure 2. The refrigeration in forming pasta dough might be beneficial for the batter layers to be steady in the pasta dough and lead a well texture for the puff pastry [10]. It was observed that a longer refrigeration produced a larger volume of the puff pastry. 
(a) Butter and Dough Flat

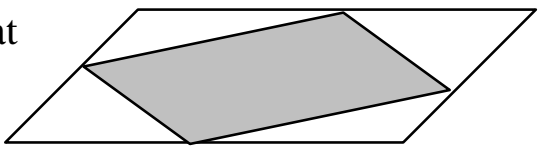

(b) Wrapping

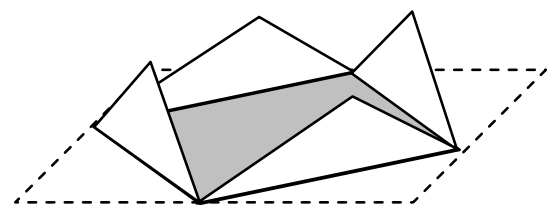

(c) Rolling out

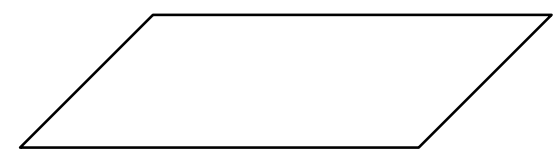

(d) Folding

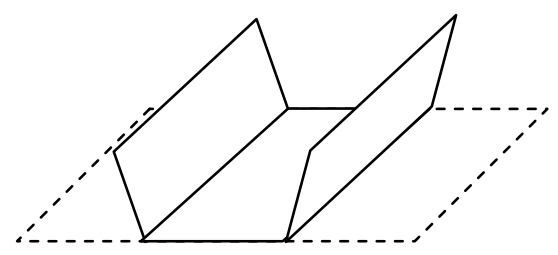

(e) Pasta dough refrigeration

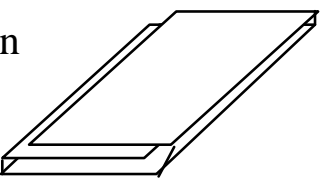

Figure 2. Folding process of pasta dough

Baking and Completing of Puff Pastry. The pasta dough with a core of nuts fragment and chocolate was baked in oven at $210^{\circ} \mathrm{C}$ for 18 minutes. After cooling at room temperature for 60 minutes, the puff pastry was topping up with the melt of chocolate and spreading nuts fragment on it for decoration.

\section{Conclusion}

It is effectible to produce a novel puff pastry with nuts application in a process along by sections of dough mixing, pasta dough forming, nuts fragment preparation and injection, baking, topping and decoration. The appropriate recipe of dough mixture especially the ratio between flour, butter and water plays an important role for the puff pastry to achieve a high quality on sensory aspects. The identified recipe of $16 \%$ strong flour, $16 \%$ weak flour, $33 \%$ butter, $13 \%$ water, $11 \%$ milk powder, $8 \%$ eggs, $2 \%$ sugar and $1 \%$ salt are optimum for the dough mixture. By the ratio of flour/butter/water at 1/1/0.4 and associated with respective roast, the introduced nuts fragment can display well crispness and strong flavour in final product. Longer refrigeration is helpful to create more expansion of the puff pastry.

\section{Acknowledgements}

This work was supported by Beijing University of Agriculture and the Research Centre funded by Harper Adams University UK. It was appreciated that Xinran Wang, Di Ou, as undergraduate students' involvement in the primary laboratory works. 


\section{References}

[1] D.S. Simovic, B. Pajin, Z. seres and N. Filipovic: Effect of Low-trans Margarine on Physicochemical and Sensory Properties of Puff Pastry. International Journal of Food Science and Technology Vol. 44(2009), pp. 1235-1244.

[2] K.S. Wickramarachchi, M.J. Sissons and S.P. Cauvain: Puff Pastry and Trends in Fat Reduction: An Update. International Journal of Food Science and Technology Vol. 50(2015), pp. 1065-1075.

[3] G.J. Besseris: Profiling Multiple Static and Transient Puff Pastry Characteristics with a robust-and -intelligent Processor. Journal of Food Enginerring Vol.164 (2015), pp. 40-54.

[4] J. Adams: Baking with Nuts and Seed. Snack Food and Wholesale Bakery Vol. July (2013), p. 12

[5] P.B. Pecivova, M. korcova, J. Svach, V. Kuban and J. Mlcek: Comparison of Chemical, Textural and Organoleptic Properties of Pastry Sheets with Two Different Additives. International Journal of Food Engineering Vol.10 (3)(2014), pp. 533-541.

[6] S. Renzetti, R.D. Harder and A, Jurgens: Puff Pastry with Low Saturated Fat Contents: The Role of Fat and Dough Physical Interactions in the Development of a Layered Structure. Journal of Food Enginerring Vol.170 (2015), pp. 24-32

[7] P.G. Macias, M.H. Gordon, R.A. Frazier, K. Smith and L. Gambelli: Performance of Plam-based Fat Blends with a Low Saturated Fat Content in Puff Pastry. Eur.J.Lipid Sci. Technol Vol. 113 (2011), pp.1474-1480.

[8] R.L. Hay: Effect of Flour Quality Characteristics on Puff Pastry Baking Performance Vol. 70(4) (1993). pp.392-396.

[9] E. Lefebure, S. Ronkart, Y. Brostaux, F. Bera, C. Blecker and S. Danthine: Investigation of the Influence of Processing Paramaters on Physicochemical Properties of Puff Pastry Margarines Using Surface Response Methodology. LWT-Food Science and Technology Vol. 51(2013), pp.225-232.

[10] S. Ronholt, J.J.K. Kirkensgaard and K. Mortensen: The Effect of Capacity, Rotational Speed and Storage on Crystallization and Rheological Properties of Puff Pastry Butter. J Am Oil Chem Soc Vol. 91 (2014), pp.29-38 